\title{
Pediatrik Adenotonsillektomi Operasyonlarında Desfluran ile Sevofluran Etkilerinin Karşılaştırılması
}

\author{
Muharrem Koçyiğit ${ }^{1} \oplus$, Özgen Ilgaz Koçyiğit ${ }^{1} \oplus$, Meltem Güner Can ${ }^{1} \oplus$, 0ya Kutlay²®
}

${ }^{1}$ Acıbadem Universitesi, Anesteziyoloji ve Reanimasyon Anabilim Dalı, İstanbul, Türkiye

${ }^{2}$ Medicabil Hastanesi, Anesteziyoloji ve Reanimasyon Kliniği, Bursa, Türkiye

Muharrem Koçyiğit, Dr. Öğr. Üyesi Özgen Ilgaz Koçyiğit, Öğr .Gör. Dr. Meltem Güner Can, Doç. Dr. Oya Kutlay, Prof. Dr.

İletişim:

Dr. Öğr. Üyesi Muharrem Koçyiğit Acıbadem Üniversitesi, Anesteziyoloji ve Reanimasyon Anabilim Dalı, İstanbul, Türkiye Tel: +902123044820

E-Posta: muharremkocyigit@hotmail.com

\section{ÖZET}

Amaç: Adenoidektomi ve adenotonsillektomi operasyonları çocukluk çağında sıklıkla yapılan günübirlik cerrahi işlemlerdendir. Kan,doku ve yağda düşük çözünürlüğe sahip inhalasyon anestezikleri, hızı indüksiyon ve derlenme sağlaması ile günübirlik cerrahi için iyi bir seçenektir.Bu çalışmamızda desfluran ve sevofluran inhalasyon anestezik ilaçlarının çocuk olgularda hemodinamik etkileri ve derlenme kalitelerinin karşılaştııııası amaçlanmıştır.

Hastalar ve Yöntemler: Adenoidektomi ve adenotonsillektomi operasyonu uygulanacak ASA I grubuna dahil, 3-10 yaşlarında, 52 olgu çalışmaya alındı. Tüm olgular rastgele iki gruba ayrıldı: Grup D ve Grup S. Standard anestezi indüksiyonu uygulandıktan sonra anestezi idamesi için \%40 0ksijen (02) - \%60 Azot protoksit (N20) ile birlikte Grup D'de \%4 desfluran uygulanırken Grup S'de \%2 sevofluran uygulandı. İndüksiyon zamanı, entübasyon zamanı, operasyonun 1., 5., 15. ve 30. dakikalarında, cerrahi bitiş ve ekstübasyon zamanında kalp atım hızı (KAH), ortalma arteryel basınç (OAB) ve periferik oksijen satürasyon (Sp02) değerleri kaydedildi. Olguların cerrahi, anestezi ve ekstübasyon süreleri kaydedildi. Olgular Derlenme Ünitesinde 20 dakika gözlendi. Modifiye Aldrete skalası ve Ağrı-konfor skalası ile anesteziden derlenmenin kalitesi değerlendirildi.

Bulgular: Her iki grupta demografik özellikler ve hemodinamik etkiler benzer bulundu. Ekstübasyon zamanı Grup D'de daha kısa bulundu $(p<0,05)$. Ayllma ünitesinde Modifiye Aldrete skala değerleri Grup D'de daha yüksek $(p<0,05)$, Grup S'de ajitasyon insidansı daha yüksek olduğu tespit edildi $(p<0,05)$.

Sonuç: Pediatrik günübirlik olgularda, desfluran daha hızı derlenme süresi ve daha az ajitasyon insidansı sağlanması nedeniyle, sevoflurana göre daha iyi bir seçenek olabilir.

Anahtar sözcïkler: Desfuran, Sevofluran, ajitasyon, adenoidektomi

A COMPARISON OF THE EFFECTS OF DESFLURANE AND SEVOFLURANE IN PEDIATRIC ADENOTONSILLECTOMY OPERATIONS

\section{ABSTRACT}

Objectives: Adenoidectomy and adenotonsillectomy operations are ambulatory (Outpatient) surgeries that are common in pediatric patients. The anesthetics agents which have low blood-tissue-lipid solubility is a good choice for the ambulatory surgery due to rapid induction and emergence. The purpose of this study was to compare the hemodynamic effects and the quality of recovery from desflurane and sevoflurane anesthesia in pediatric patients.

Patients and Methods: Fifty-two ASA physical status I patients, aged between 3-10 that underwent adenoidectomy and adenotonsillectomy were studied. Patients were randomly assigned into two groups: Group D and Group S. After the standard anesthesia induction, $4 \%$ desflurane in Group D and $2 \%$ sevoflurane in Group $S$ were administered with $40 \%$ oxygen - $60 \%$ nitrous oxide for maintenance of anesthesia. Heart rate, Mean arterial pressure and oxygen saturation were recorded before induction, after induction, at intubation, 1., 5., 15., 30. minutes and at the end of the operation and after the extubation. Operation time, anesthesia time and the extubation time were recorded. Patients have stayed in the post-anesthesia care unit for 20 minutes. Modified Aldrete score and the pain-discomfort scale were used to evaluate the quality of emergence from anesthesia.

Results: The demographic data and hemodynamic parameters were similar between the two groups. Extubation time was shorter in the desflurane group $(p<0,05)$. Modified Aldrete scores were higher in Group $D(p<0,05)$ and agitation incidence was higher in Group $S$ in recovery unit $(p<0,05)$.

Conclusion: In pediatric ambulatory patients, compared to sevoflurane, desflurane may be a better choice because of its faster recovery time and the lower incidence of agitation.

Keywords: Desflurane, Sevoflurane, agitation, adenoidectomy 
A denoidektomi ve adenotonsillektomi, çocukluk döneminde günübirlik cerrahi olarak sıklıkla yapılan operasyonlardır (1). Bu operasyonlarda ideal bir anestezi yönetiminde; anestezi indüksiyonunun hızlı olması, intraoperatif hemodinamik stabilitenin sağlanması, anesteziden çıkışın hızlı, erken derlenme döneminin konforlu olması beklenir. Cerrahi sonrasında, etkin bir analjezi sağlanmalı, beraberinde bulantı, kusma, kanama ve ajitasyon sıklığı azaltılmalıdır (2).

Günübirlik olgularda hızlı derlenme sağlamak için sık olarak; anestezi indüksiyonunda, propofol, kısa etkili opioid ve kısa etkili kas gevşetici ile anestezi idamesinde desfluran veya sevofluran gibi kan-gaz çözünürlüğü düşük olan ve hızlı derlenmeyi sağlayan inhalasyon ajanları kullanılmaktadır. Cerrahi sonrasında, etkin bir postoperatif analjezi ile birlikte bulantı, kusma, kanama ve ajitasyon gibi komplikasyonların azaltılması amaçlanmalıdır (3). Derlenme dönemi ajitasyonu azaltma amacı ile fentanil, ketamin, ketoralak ve deksmedetomidin kullanımı bildirilmiştir (4-7).

Bu çalışma ile adenoidektomi ve adenotonsillektomi cerrahisi uygulanacak pediatrik hastalarda, sevofluran ve desfluran anestezilerinin peroperatif hemodinamik değişimler, postoperatif derlenme hızı ve kalitesi yönünden karşılaştııılması amaçlanmıştır.

\section{Hastalar ve yöntemler}

Bu prospektif, randomize klınik çalışma, Üniversite Tıp Fakültesi Etik Kurulu'nun (2003-3/13) onayı ve adenoidektomi - adenotonsillektomi operasyonu olacak çocukların ebeveynlerinin yazılı onayı ile yapıldı.

Çalışmaya, ASA (American Society of Anesthesiologists) sınıflandırması I grubundan yaşları 3-10 arasında olan 21'i erkek, 31'i kız toplam 52 çocuk hasta alındı. Gelişme geriliği, uyku apnesi, hava yolu hastalığı hikayesi, anestezik ilaçlara karşı alerji öyküsü olan, antihistaminik, santral sinir sistemini etkileyen ilaç kullanan, ASA II-IV sınıfından olgular çalışma dışı bırakıldı. Hiçbir hastaya premedikasyon uygulanmadı.

Operasyon odasına alınan tüm olgulara üç kablolu tek derivasyonlu elektrokardiyogram (EKG) monitörizasyo$\mathrm{nu}$, periferik oksijen satürasyonu $\left(\mathrm{SpO}_{2}\right)$, noninvaziv kan basıncı monitörizasyonu yapıldıktan sonra 22G (gauge) veya $24 \mathrm{G}$ kateter ile intravenöz (iv) damar yolu açıldı. Hesaplanan saatlik sıvı ihtiyacına göre $\% 5$ dekstroz - \%0,2 sodyum klorür solüsyonu infüzyon uygulandı.
Tüm olguların anestezi indüksiyonu propofol ( $2 \mathrm{mg} / \mathrm{kg}$, iv), fentanil $(2 \mu \mathrm{g} / \mathrm{kg}$, iv); kas gevşekliği, mivakuryum (0,2 mg/ $\mathrm{kg}$, iv) ile sağlandı. Mivakuryumun iv uygulamasından 2 dakika sonra Macintosh tipi laringoskop kullanılarak yaşına uygun boyda balonlu spiralli endotrakeal tüp ile trakeal entübasyon gerçekleştirildi.

Olgular rastgele 2 gruba ayrıldı: Grup D ve Grup S. Entübasyon sonrası anestezi idamesi için \%40 Oksijen $\left(\mathrm{O}_{2}\right)$ - \%60 Azot protoksit $\left(\mathrm{N}_{2} \mathrm{O}\right)$ karışımı içinde Grup D olgularına $(n=26)$ desfluran (\%4); Grup S olgularına $(n=26)$ sevofluran (\%2) anestezisi uygulandı.

Operasyon sonunda cerrahın belirtmesi ile uygulanan inhalasyon anestezik ilaç kesildi ve $5 \mathrm{lt} / \mathrm{dk}$ akımda \%100 $\mathrm{O}_{2}$ ile ventilasyona geçildi. Orofarinks aspire edildi ve yeterli spontan solunum gözlendikten sonra olgular ekstübe edildi. Hiçbir olguda nöromusküler bloker antagonisti kullanılmadı.

Olguların kalp atım hızı (KAH), ortalama arter basıncı (OAB) ve periferik oksijen satürasyonu $\left(\mathrm{SpO}_{2}\right)$ değerleri (anestezi öncesi, anestezi indüksiyonu sonrası, intübasyon sonrası, operasyonun 1., 5., 15. ve 30. dakikalarında, cerrahi bitiminde ve ekstübasyon sonrasında) ile cerrahi, anestezi ve ekstübasyon süreleri kaydedildi.

Ekstübasyon zamanı; inhalasyon anestezik ilaçlarının kesilmesi ve $\% 100 \mathrm{O}_{2}$ ile inhalasyon sağlandığı zamandan ekstübasyona kadar geçen süre olarak belirlendi.

Anestezi indüksiyonu ve entübasyon sırasında öksürük, ıkınma, nefes tutma, laringospazm, bronkospazm, peroperatif disritmi, operasyon sonu laringospazm, bronkospazm, kanama, bulantı ve kusma olup olmadığı kaydedildi.

Ekstübasyon sonrası operasyon odasında ve uygulanan inhalasyon anesteziğinden habersiz doktor tarafından derlenme ünitesinde tüm olgularda 1.,5.,10. ve 20. dakikalarda modifiye Aldrete skorlama sistemi (Tablo 1) ile anesteziden derlenmenin, Ağrı - Konfor skalası (Tablo 2) ile anesteziden uyanmanın kalitesi değerlendirildi (8).

Modifiye Aldrete skorlamasında en yüksek toplam puan olan 8'e ulaşma iyi derlenme olarak, Ağrı-Konfor skalasında toplam puan 3'ün üzerinde olması ajitasyon olarak değerlendirildi.

\section{istatistiksel analiz}

Elde edilen numerik verilerin gruplar arası karşılaştııımasında Student's t ve Mann Whitney U testi, kategorik 


\section{Tablo 1. Modifiye aldrete skorlama}

\begin{tabular}{lcc} 
Değerlendirme & Durum & Puan \\
\hline Aktivasyon & Hareketsizlik & 0 \\
& İstemsiz hareket & 1 \\
& İstemli hareket & 2 \\
Solunum & Apne & 0 \\
& Yüzeyel solunum & 1 \\
Bilinç Düzeyi & Derin solunum / öksürük & 2 \\
& Cevapsızlık & 0 \\
& Uyarıya cevap & 1 \\
Periferik Oksijen Saturasyonu & Tam uyanık & 2 \\
$\left(\mathrm{SpO}_{2}\right)$ & $<\% 90$ & 0 \\
& $\% 90-94$ & 1 \\
& $\geq \% 95$ & 2
\end{tabular}

Tablo 2. Ağrı - konfor skalası

\begin{tabular}{lcc} 
Değerlendirme & Durum & Puan \\
\hline Ağlama & Yok & 0 \\
& Konfora bağımlı & 1 \\
Konfordan bağımsız & 2 \\
Hareket & Hareketsizlik & 0 \\
& İstemsiz hareket & 1 \\
Ajitasyon & Husursuz hareket & 2 \\
& Sakin & 0 \\
& Orta derece & 1 \\
& Ciddi ajitasyon & 2
\end{tabular}

verilerin karşılaştırılmasında Chi-square ve Fisher's Exact testi, grup içi karşılaştırılmada paired t test kullanıldı. Veriler ortalama \pm standart sapma olarak verildi. $p<0,05$ anlamlı olarak kabul edildi

\section{Bulgular}

Her iki grup, demografik özellikler, operasyon tipi ve dağııımı bakımından benzer bulundu. $(p>0,05)$ (Tablo 3 ).

İndüksiyon dönemi KAH, Grup S'de Grup D'ye göre istatistiksel olarak anlamlı derecede yüksek bulundu $(p<0,01)$. Gruplar arasında diğer dönemlerde KAH bakımından anlamlı bir farklılık oluşmadı (Tablo 4).

Ortalama arter basınç değerleri bakımından gruplar arasında istatistiksel olarak anlamlı fark saptanmadı ( $p>0.05$ ) (Tablo 5).
Tablo 3. Olguların demografik özellikleri, operasyonlar ve süreler (Ort. \pm SS $)(p<0.05)^{*}$

Grup $D(n=26)$

Grup $S(n=26)$

\begin{tabular}{lcc}
\hline Cinsiyet (E/K) & $10(\% 38,5) / 16(\% 61,5)$ & $11(\% 42,3) / 15(\% 57,7)$ \\
Yaş (yıl) & $6,35 \pm 2,31$ & $5,88 \pm 2,36$ \\
Ağırlık (kg) & $22,88 \pm 8,40$ & $23,15 \pm 11,20$ \\
Boy (cm) & $114,77 \pm 15,13$ & $110,31 \pm 17,93$ \\
Adenoidektomi & $20(\% 76,9)$ & $20(\% 76,9)$ \\
Adenotonsillektomi & $6(\% 23,1)$ & $6(\% 23,1)$ \\
Cerrahi süre (dk) & $25,38 \pm 15,37$ & $26,73 \pm 13,63$ \\
Anestezi süresi (dk) & $36,15 \pm 16,92$ & $35,54 \pm 15,10$ \\
Ekstübasyon süresi (dk) & $4,12 \pm 1,58$ & $7,23 \pm 2,50$ *
\end{tabular}

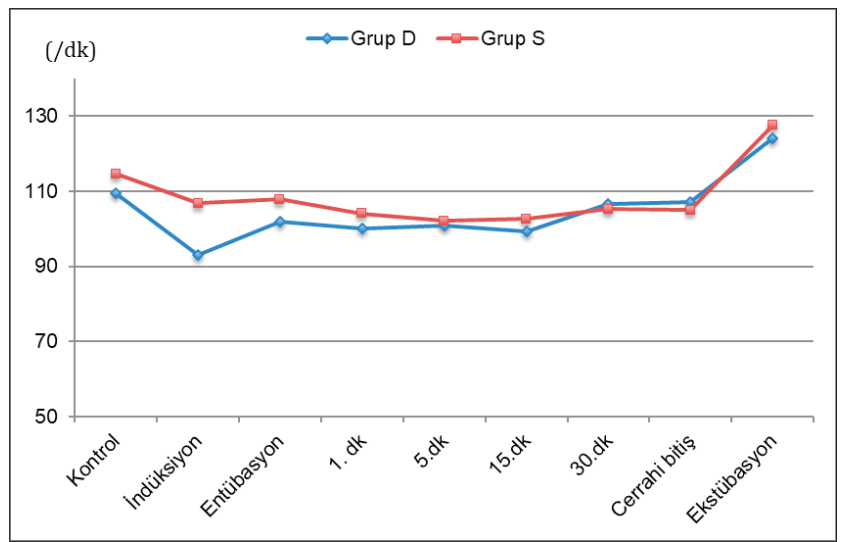

Tablo 4. Olguların kalp atım hızı (/dk) $(p>0.05)$

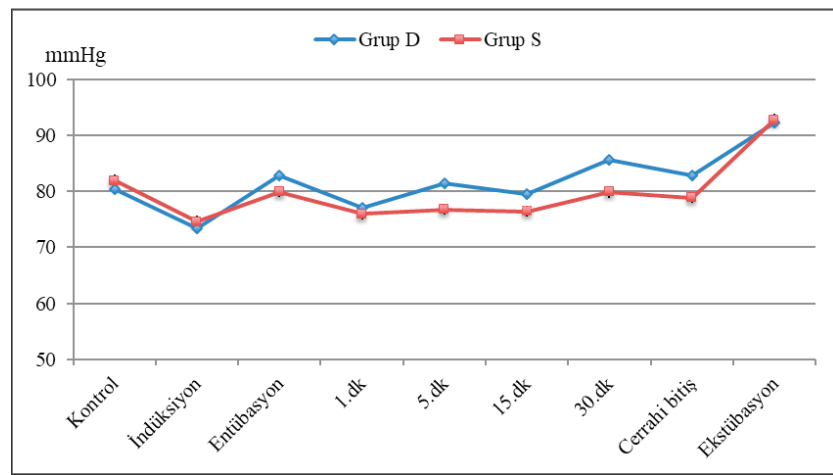

Tablo 5. Olguların ortalama arter basıncı $(\mathrm{mmHg})(p>0.05)$

Her iki grupta ekstübasyon dönemlerinde $\mathrm{KAH}$ ve $\mathrm{OAB}$ değerleri kontrol dönemine göre istatistiksel olarak anlamlı derecede yüksek bulundu $(p<0,05)$.

Gruplar arasında $\mathrm{SpO}_{2}$ düzeylerinde farklııı saptanmadı ve tüm dönemlerde $\% 98$ ve üzerinde seyretti.

Cerrahi ve anestezi süreleri bakımından her iki grup arasında istatistiksel olarak anlamlı bir farklılık saptanmadı 
( $p>0,05)$. Grup D'nin ekstübasyon süreleri Grup S'ye göre anlamlı derecede kısa idi $(p<0,05)$ (Tablo 3 ).

Modifiye Aldrete skala değerleri Grup D'de Grup S'ye göre tüm dönemlerde istatistiksel olarak anlamlı derecede yüksek bulundu $(p<0,05)$ (Tablo 6).

Tüm olgular Modifiye Aldrete skalasında $\mathrm{SpO}_{2}$ parametresinden 2 puan aldı, $\mathrm{SpO}_{2} \geq 96$ olarak belirlendi.

Ağrı-konfor skalası ortalama değerleri operasyon odasında Grup D'de, Grup S'ye göre anlamlı derecede yüksekti $(p<0,05)$. Derlenme ünitesinde 1. ve 5 . dakikalarda Ağrıkonfor skala değerlerinde gruplar arasında istatistiksel olarak fark saptanmadı ( $p>0,05)$. Fakat 10. ve 20. dakikalarda Ağrı-konfor skala ortalama değerleri Grup S'de, Grup D'ye göre istatistiksel olarak anlamlı derecede yüksekti $(p<0,05)$ (Tablo 6)

Her iki grup arasında operasyon odası, derlenme ünitesi 1 . ve 5 . dakikalarda ajitasyon sıklığı bakımından istatistiksel olarak anlamlı bir farklılık saptanmadı $(p>0,05)$. Derlenme ünitesi 10. ve 20. dakikalarda ajitasyon sıklığı Grup S'de istatistiksel olarak anlamlı derecede fazla idi $(p<0,01)$ (Tablo 6).

Her iki grupta indüksiyon ve entübasyon dönemlerinde öksürük, ıkınma, laringospazm ve bronkospazm; operasyon boyunca disritmi ve operasyon sonunda laringospazm, bronkospazm ve kanama görülmedi. Hiçbir olguda alerjik reaksiyon, vücutlarında kızarıklık ve döküntü gözlenmedi. Operasyon sonu derlenme ünitesinde 20 dakikalık gözlem süresinde hiçbir olguda bulantı ve kusma tespit edilmedi.

\section{Tartışma}

Günübirlik olgularda hızlı derlenme sağlamak için sık olarak; anestezi indüksiyonunda, propofol, kısa etkili opioid ve kısa etkili kas gevşetici ile anestezi idamesinde desfluran veya sevofluran gibi kan-gaz çözünürlüğü düşük olan inhalasyon ajanları kullanılmaktadır (9) Bunun için cerrahi sonrasında hızlı derlenme, etkin bir postoperatif analjezi ile birlikte bulantı, kusma, kanama ve ajitasyon gibi komplikasyonların az olmasını sağlayan anestezik ilaçlar kullanılmalıdır (10). Modern volatil anesteziklerden sevofluran ve desfluran, hızlı başlayan, sonlanan anestezik etkileri ve hemodinamik açıdan kontrol edilebilir etkileri nedeniyle kısa süreli cerrahi girişimlerde sıkça kullanılmaktadır.

Çalışmamızda adenoidektomi ve adenotonsillektomi uygulanan çocuklarda, gerek desfluran, gerekse sevofluran anestezisinin benzer düzeyde hemodinamik stabilite sağladıkları gözlendi. İki grupta da kalp atım hızı ve ortalama arter basıncı değişiklikleri, operasyon süresince benzer şekilde seyretti ve fizyolojik sınırlar içinde kaldı.

Günübirlik anestezide istenen önemli bir özellik de operasyon bitiminde hastaların hızı uyanmasıdır. Anesteziden hızlı derlenme, günübirlik anestezi uygulamalarında önemli olan havayolu reflekslerinin geri dönüşünü hızlandırır ve havayolunun güvenli şekilde korunmasını sağlar (9). Operasyon sonu havayolu obstrüksiyonu her zaman olasıdır, bu yüzden koruyucu havayolu reflekslerinin erken geri dönüşü derlenmenin en önemli aşamasıdır (10).

Çalışmamızdaki olgularımızın hiçbirinde operasyon sonu kanama, laringospazm, bronkospazm ve $\mathrm{SpO}_{2}$ düşmesi görülmemiş, havayolu güvenli şekilde korunabilmiştir.

Gerek desfluran, gerekse sevofluran, kan/gaz eriyirlik katsayılarının düşük olması nedeniyle anestezi bitiminde hızlı uyanma sağlarlar. Çalışmamızda hem desfluran, hem de sevofluran anestezisi ile ortalama 4-7 dk içinde derlenme sağlanmıştır. Buna karşııık, adenoidektomi operasyonlarında desfluran ve sevofluran uygulanan hastalarda operasyon sonu derlenmenin desfluran uygulanan hastalarda

Tablo 6. Grupların değerlendirme ve karşılaştırma sonuçları

\begin{tabular}{lcccccc} 
& \multicolumn{2}{c}{ Modifiye Aldrete Skala Değerleri } & \multicolumn{2}{c}{ Ağrı-Konfor Skala Değerleri } & \multicolumn{2}{c}{ Ajitasyon Sıklık Değerleri } \\
\hline & Grup D & Grup S & Grup D & Grup S & Grup D & Grup S \\
\hline OR & $6,50 \pm 1,03^{*}$ & $5,00 \pm 1,26$ & $2,69 \pm 1,28^{*}$ & $1,58 \pm 1,52$ & $6(\% 23,1)$ & $2(\% 7,7)$ \\
DÜ 1. dk & $7,50 \pm 0,76^{*}$ & $6,38 \pm 0,94$ & $3 \pm 1,49$ & $2,62 \pm 1,74$ & $9(\% 34,6)$ & $8(\% 30,8)$ \\
DÜ 5. dk & $7,85 \pm 0,61^{*}$ & $7,15 \pm 0,88$ & $2,92 \pm 1,41$ & $3,04 \pm 1,66$ & $8(\% 30,8)$ & $10(\% 38,5)$ \\
DÜ 10. dk & $8,00^{*}$ & $7,69 \pm 0,55$ & $2,58 \pm 1,13$ & $3,62 \pm 1,6^{*}$ & $5(\% 19,2)$ & $14(\% 53,8)^{*}$ \\
DÜ 20. dk & $8,00^{*}$ & $7,85 \pm 0,37$ & $2,19 \pm 0,63$ & $3,69 \pm 1,6^{*}$ & $1(\% 3,8)$ & $14(\% 53,8)^{*}$ \\
\hline
\end{tabular}

OR: Operasyon Odası, DÜ: Derlenme Ünitesi (Ort. \pm SS)

Gruplar arası farkllik: $(p<0.05)^{*}$ 
daha hızlı olduğunu bildiren çalışmalara paralel olarak bizim çalışmamızda da Grup D'de daha hızlı ekstübasyon sağlanmıştır (9-11).

Günübirlik cerrahide kısa etki süreli nöromusküler blokörlerin kullanılması hızlı derlenmeye katkıda bulunabilir. Tek doz $0.2 \mathrm{mg} / \mathrm{kg}$ iv mivakuryum uygulamasından 16-18 dakika sonra \%95 oranında derlenme görüldüğü ve derlenmenin çocuklarda erişkinlere göre daha hızlı olduğu bildirilmiştir (12). Mivakuryum dozunun 0,3 mg/kg'a çıarılmasının derlenme süresini uzatmadığı bildirilmiştir (13). Bizim çalışmamızda da mivakuryum $0,2 \mathrm{mg} / \mathrm{kg}$ olarak uygulandı. Çalışmamızda cerrahi süreler heriki grupta ortalama $25 \mathrm{dk}$ oldu, dolayısıyla mivakuryum etkisinin kendiliğinden sonlanması için cerrahi süre yeterli olmuştur.

Desfluran ve sevofluran gibi volatil anesteziklerin bir dezavantajı, analjezik etkilerinin olmamasıdır. Bu amaçla sık olarak intraoperatif dönemde opioid ajanlardan yararlanımaktadır. Günübirlik cerrahide kullanılacak opioidlerin, derlenmeyi geciktirmeyecek kadar kısa etki süreli olması tercih edilmektedir. Çalışmamızda, intraoperatif analjezi, fentanil ile sağlanmıştır. Fentanilin kısa etki süresinin operasyon bitiminde uyanmayı geciktirmeyeceği düşünülmüştür (9).

Günübirlik cerrahi uygulanacak hastaların anestezisinde hızlı derlenmeyi sağlamak üzere tercih edilen stratejilerden birisi de azot protoksit kullanarak, diğer volatil anesteziklerin konsantrasyonlarının düşük tutulmasıdır. Azot protoksit kullanılması volatil anestezik ilaçların gereksinimini azaltmakta, dolayısıyla derlenme daha hızlı olabilmektedir. Fakat orta kulakta basınç artımına neden olarak vestibuler sistemi uyarmakta ve gastrointestinal sistemde basınç artışı yaparak bulantı, kusma insidansını artırmaktadır (14). Ancak pediatrik tonsillektomi olgularında azot-protoksitin kullanımı ile kusma insidansında artışın görülmediği bildirilmiştir (15). Bizim çalışmamızda da azot protoksit kullanımının derlenme süresini kısalttığı düşüncesindeyiz. Aynı zamanda hiçbir olgumuzda bulantı ve kusma gözlenmemiştir.

Günübirlik cerrahide postoperatif bulantı ve kusma oluşması, hasta konforunu olumsuz yönde etkileyen ve sık görülebilen faktörlerden birisidir. Desfluran anestezisi de postoperatif dönemde bulantı ve kusma nedeni olabilir. Desfluran anestezisi altında adeno-tonsillektomi operasyonu geçiren hastaların $\% 65$ 'inde kusma görüldüğü bildirilmiştir (9). Bizim çalışmamızda ise derlenme ünitesindeki takipleri süresince, hiçbir olguda bulantı ve kusma gözlenmemiştir.
Pediatrik olgularda postoperatif dönemde bulantı ve kusma riskini arttıran faktörlerden birisi de nöromusküler blokörlerin etkisini ortadan kaldırmak üzere asetilkolinesteraz enzim inhibitörlerinin kullanılmasıdır (13). Çalışmamızda nöromusküler bloker ilaç olarak kısa etkili mivakuryum kullanılması operasyon bitiminde hiçbir olguda kas gevşetici antagonisti kullanılmamasını sağlamış, dolayısıyla günübirlik anestezi işlemlerinde hasta taburculuğunu geciktirebilecek olan neostigmin kullanımına bağlı bulantı, kusma engellenmiştir.

Desfluran ve sevofluran gibi etkisi hızlı sonlanan inhalasyon anestezisi alan çocuklarda, anesteziden uyanıklığa hızlı geçiş ajitasyona neden olabilir. Derlenme sonrası görülen ajitasyon; hastanın yataktan düşmesine, kendisini yaralamasına veya damar yolunun çıkmasına neden olabilir (2). Bu nedenle sürekli bir izlem ve transport işlemleri sırasında da daha fazla dikkat gerekmektedir (16). Yabancı bir alanda bilincin hızla yerine gelmesi, kendisiyle ilgilenen yabancı kişilerin olması çocukta altta yatan endişe ve korkuyu şiddetlendirebilir (11). Bunun yanında okul öncesi yaş grubunda olan çocukların psikolojik olarak daha az olgun ve kooperasyon için daha az yetenekli olmalarından dolayı yabancı bir ortamda derlenmelerinin deliryum insidansında artışa neden olabileceği de belirtilmiştir (17).

Sevofluran anestezisi altındaki ameliyatlar sonrasında ajitasyon insidansı \%14-67 arasında değişmektedir $(11,18)$. Sevofluran anestezisi altında ağrılı bir işlem olmayan magnetik rezonans görüntülemesi yapılan 0,5-10 yaş grubu çocuklarda uygulananlarda işlem sonrası ajitasyon insidansının \%29-33 olduğu belirtilmiştir (19). Ürolojik operasyonlar geçiren pediatrik hastalarda desfluran ve sevofluran anestezisi sonrası ağrı, hipoksi ve metabolik bozukluğa bağlı olmaksızın ajitasyon görüldüğü bildirilmiştir (17). Sevofluran anestezisi alan hastalar ile anestezi indüksiyon ve idamesinin propofol ile sağlandığı hastaların karşılaştırıldığı bir çalışmada, anestezi sonrası ajitasyonun belirgin olarak sevofluran grubunda fazla olduğu bildirilmiştir $(16,20)$. Sevofluran ve azot-protoksitin birlikte uygulandığı pediatrik hastalarda sadece sevofluran uygulanan hastalara göre ajitasyon insidansının 7 kat daha az olduğu bildirilmiştir (21).

Bizim çalışmamızda ise sevofluran anestezisi uygulanan grupta ajitasyon insidansının operasyon odasında \%7,7 iken, ayılma ünitesinde 20 . dakikada $\% 53,8$ 'e yükseldiği tespit edilmiştir. 
Desfluranın hızlı derlenme sağlamasından dolayı çocuklarda operasyon sonu ajitasyon insidansının \%24-50 oranında görüldüğü bildirilmiştir $(11,22)$. Bizim çalışmamızda ise ajitasyon insidansı, desfluran anestezisi uygulanan grupta derlenme ünitesinde zaman içinde azalırken (\%34,6'dan, \%3,8'e) sevofluran anestezisi uygulanan grupta ise artmıştır (\%30,8'den, \%53,8'e).

Anestezi sonrası ajitasyon insidansı en çok ilk 20 dakika içinde görülmektedir (10). Operasyon sonrası ajitasyon nedeni kesin olarak bilinmemekle birlikte; hipoksi, ağrı, anksiyete, hipoglisemi, elektrolit bozukluğu ajitasyona neden olabileceği gibi ketamin, droperidol, skopolamin, atropin gibi ilaçların kalıcı etkilerine bağlı olarak da görülebilir $(2,16,20)$. Çalışmamızda hiçbir olguda operasyon sonrası hipoksi görülmedi. Tüm olgulara operasyon boyunca glukoz ve sodyum içeren solüsyon infüzyonları

\section{Kaynaklar}

1. Patel A, Davidson M, Tran MC, Quraishi H, Schoenberg C, Sant M, et al. Dexmedetomidine infusion for analgesia and prevention of emergence agitation in children with obstructive sleep apnea syndrome undergoing tonsillectomy and adenoidectomy. Anesth Analg 2010;111:1004-10. [CrossRef]

2. Dahmani S, Stany I, Brasher C, Lejeune C, Bruneau B, Wood C, et al. Pharmacological prevention of sevoflurane- and desflurane-related emergence agitation in children: a meta-analysis of published studies. Br J Anaesth 2010;104:216-23. [CrossRef]

3. Edler AA, Mariano ER, Golianu B, Kuan C, Pentcheva K. An analysis of factors influencing postanesthesia recovery after pediatric ambulatory tonsillectomy and adenoidectomy. Anesth Analg 2007;104:784-9. [CrossRef]

4. Cohen IT, Hannallah RS, Hummer KA. The incidence of emergence agitation associated with desflurane anesthesia in children is reduced by fentanyl. Anesth Analg 2001;93:88-91. [CrossRef]

5. Lee YS, Kim WY, Choi JH, Son JH, Kim JH, Park YC. The effect of ketamine on the incidence of emergence agitation in children undergoing tonsillectomy and adenoidectomy under sevoflurane general anesthesia. Korean J Anesthesiol 2010;58:440-5. [CrossRef]

6. Park JH, Lim BG, Kim HZ, Kong MH, Lim SH, Kim NS, Lee IO. Comparison of emergence agitation between sevoflurane/ nitrous oxide administration and sevoflurane administration alone in children undergoing adenotonsillectomy with preemptive ketorolac. Korean J Anesthesiol 2014;66:34-8. [CrossRef]

7. Kim HS, Byon HJ, Kim JE, Park YH, Lee JH, Kim JT. Appropriate dose of dexmedetomidine for the prevention of emergence agitation after desflurane anesthesia for tonsillectomy or adenoidectomy in children: up and down sequential allocation. BMC Anesthesiol 2015;15:79. [CrossRef]

8. Sury MRJ, Black A, Hemington L, Howard R, Hatch DJ, Mackersie A. A comparison of recovery characteristics of sevoflurane and halothane in children. Anaesthesia 1996;51:543-6. [CrossRef]

9. Cohen IT, Finkel JC, Hannallah RS, Hummer KA, Patel KM. The effect of fentanyl on the emergence characteristics after desflurane or sevoflurane anesthesia in children. Anesth Analg 2002;94:1178-81. [CrossRef]

10. Cohen IT, Drewsen S, Hannallah RS. Propofol or midazolam do not reduce the incidence of emergence agitation associated with desflurane anaesthesia in children undergoing adenotonsillectomy. Paediatr Anaesth 2002;12:604-9. [CrossRef] uygulandı. Hiçbir hastada kas gevşeticinin etkisini geri döndürücü ilaç ve antikolinerjik ilaç kullanılmadı. Bu nedenle, çalışmamızda görülen Postoperatif ajitasyonun, inhalasyon anesteziklerinin etkisinin hızlı bir şekilde sonlanmasına bağlı olduğunu düşünüyoruz.

Sonuç olarak; çalışmamızda çocukluk çağında yaygın olarak uygulanan ve günübirlik anestezi yönetiminin de önemli olduğu adenoidektomi ve adenotonsillektomi operasyonlarında; sevofluran ve desfluran anestezilerinin intraoperatif dönemde iyi hemodinamik stabilite sağladığı, postoperatif dönemde bulantı ve kusmaya neden olmadığı belirlendi. Desfluran uygulanan pediatrik hastalarda derlenme döneminde daha düşük oranda ajitasyon görülmesi nedeni ile günübirlik anestezi uygulamalarında avantajlı olabileceği düşüncesindeyiz.

11. Viitanen $H$, Annila $P$, Viitanen $M$, Tarkkila P. Premedication with midazolam delays recovery after ambulatory sevoflurane anesthesia in children. Anesth Analg 1999;89:75-9. [CrossRef]

12. Shorten GD, Crawford MW, Louis P. The neuromuscular effects of mivacurium chloride during propofol anesthesia in children. Anesth Analg 1996;82:1170-5. [CrossRef]

13. Watcha MF, Safavi FZ, McCulloch DA, Tan TSH, White PF. Effect of antagonism of mivacurium-induced neuromuscular block on postoperative emesis in children. Anesth Analg 1995;80:713-17. [CrossRef]

14. Watcha MF, White PF. Postoperative nausea and vomiting: its etiology, treatment, and prevention. Anesthesiology 1992;77:16284. [CrossRef]

15. Pandit UA, Malviya S, Lewis IH. Vomiting after outpatient tonsillectomy and adenoidectomy in children: The role of nitrous oxide. Anesth Analg 1995;80:230-3. [CrossRef]

16. Uezono S, Goto T, Terui K, Ichinose F, Ishguro, Nakata Y, Morita S. Emergence agitation after sevoflurane versus propofol in pediatric patients. Anesth Analg 2000;91:563-6. [CrossRef]

17. Aono J, Ueda W, Mamiya K, Takimoto E, Manabe M. Greater incidence of delirium during recovery from sevoflurane anesthesia in preschool boys. Anesthesiology 1997;87:1298-300. [CrossRef]

18. Lapin SL, Auden SM, Goldsmith LJ, Reynolds AM. Effects of sevoflurane anaesthesia on recovery in children: a comparison with halothane. Paediatr Anaesth 1999;9:299-304. [CrossRef]

19. Costi D, Ellwood J, Wallace A, Ahmed S, Waring L, Cyna A. Transition to propofol after sevoflurane anesthesia to prevent emergence agitation: a randomized controlled trial. Paediatr Anaesth 2015;25:517-23. [CrossRef]

20. Picard V, Dumont L, Pellegrini M. Quality of recovery in children: sevoflurane versus propofol. Acta Anaesthesiol Scand 2000;44:30710. [CrossRef]

21. Sarner J B, Levine M, Davis PJ, Lerman J, Cook DR, Motoyama EK. Clinical characteristics of sevoflurane in children. Anesthesiology 1995;82:38-46. [CrossRef]

22. Welborn LG, Hannallah RS, Norden JM, Ruttimann UE, Callan CM. Comparison of emergence and recovery characteristics of sevoflurane, desflurane, and halothane in pediatric ambulatory patients. Anesth Analg 1996;83:917-20. [CrossRef] 